\title{
MONTES Y BOSQUES DE ORIHUELA EN LOS SIGLOS XVI Y XVII
}

\author{
José Ojeda Nieto \\ IES «El Palmeral» \\ Orihuela, Alicante
}

\section{RESUMEN}

Los montes y los bosques de la época Moderna son poco conocidos. Escasean los documentos, y cuando los hay se fijan en las talas y abusos cometidos por los vecinos o en las preocupaciones - normativas concejiles - de buena utilización de la leña y la madera. La Orihuela foral, siglos XVI y XVII, gozaba de una amplia extensión de terrenos comunales donde el pastoreo convivía con el aprovechamiento silvícola. El presente estudio marca los límites del monte, concretamente del arbolado, al tiempo que cuantifica, como propuesta, los distintos espacios que configuraban el paisaje del Bajo Segura: huerta, boalares, redondas y realengo. Normas y leyes que reglamentaban cortes y talas, así como los malos usos del bosque - carboneo e incendios-, son también analizados para entender el proceso de deforestación y su control a lo largo de las citadas centurias.

Palabras clave: Bajo Segura, Orihuela, siglos XVI y XVII, monte, bosque, incendios, talas, deforestación.

\section{ABSTRACT}

Woodland and forest are scarcely known in the Modern era. Lack of documentation, when found, shows the cut down and the abuse carried out by neighbours and brings to light the concern about the appropriate use of the wood and firewood, taking into account the council rules. Orihuela foral on the 16th and 17th century benefits from a broad expanse of communal lands where pasturing coexist with the forestry exploitation. The current issue sets the boundaries of the woodlands, in particular about the trees, while at the same time quantify, as a proposition, the diverse spacious found in the Bajo Segura landscape: irrigated agriculture, boalares, redondas y realengo. Policies and laws about the regulations of cuttings and cut down of trees are analysed along with the misuse of woodlands, coal works and fires, to understand the deforestation and its control through the centuries mentioned.

Key words: Bajo Segura, Orihuela, 16th and 17th century, woodland, forest, fires, cut down, deforestation. 


\title{
Montes y bosques de Orihuela en los siglos XVI y XVII
}

\author{
... Si en comiença[n] a cortar un enzinal para leña \\ no saben entrecriar unos árboles nuevos entre tanto \\ que gastan lo viejo... No sé si lo haze alguna mala \\ constelació[n] que tenemos los españoles o poco cui- \\ dado de lo venidero ${ }^{1}$.
}

Nada más apropiado que las palabras de Alonso de Herrera para recordar el abandono - la destrucción se diría mejor- al que estuvo sometido el bosque de la España de las décimo quinta y décimo sexta centurias. Alonso de Herrera ${ }^{2}$, que vivió a caballo de los siglos XV y XVI, viajero, estudioso de la Naturaleza y de la agricultura, hubo de conocer, sin duda, las leyes de los Reyes Católicos defendiendo los bosques, mas Alonso también hubo de otear los montes en sus viajes y constatar la situación en la que se hallaban. Estaría al tanto - lo deja entrever en su escrito-, de las invasiones por parte de los nobles como por parte de pastores y comunidades locales. Y sin embargo, Alonso no llegaría a conocer el ataque que se desencadenaría en el reinado de los Austrias, especialmente desde mediados del Quinientos; más concreta y puntualmente tras la primera "desamortización", o roturaciones, producida a raíz de la venta de bienes realengos y baldíos llevada a cabo por Felipe $\mathrm{II}^{3}$. Los nuevos propietarios ampliarían así las tierras de labor ${ }^{4}$, respetando sólo aquellas zonas boscosas donde no había entrado el arado. El rey, que no fue ajeno al problema, le preocupó, y mucho al parecer, esta situación:

«Una cosa deseo ver acabada de tratar, y es lo que toca a la conservación de los montes y aumento de ellos, que es mucho menester y creo que andan muy al cabo; temo que los que vinieran después de nosotros han de tener mucha queja de que les dejemos los bosques y sus riquezas consumidas; y plegue a Dios que no lo veamos en nuestros días» ${ }^{5}$.

En resumen, los siglos XVI y XVII se caracterizaron por el incremento en la deforestación, y es que la presión se acentuó a causa de las necesidades de leña y madera. Hubo también defensores como Alonso; por ejemplo Toribio Pérez Bustamante que en 1656 escribiría — confirmándolo Felipe IV— algo muy parecido:

1 ALONSO DE HERRERA (1584): Libro de Agricultura. Lib. III, cap. XXIIII. Valencia, 1584, p. 84.

2 Nace entre 1470-80 y fallece en 1539. Un breve resumen y un análisis del libro en E. BAUER MANDERSCHEID, E. (1980): Los montes de España en la historia. Ministerio de Agricultura. Madrid, pp. 201-204.

3 GÓMEZ MENDOZA, J. (1967): «La venta de baldíos y comunales en el siglo XVI. Estudio de su proceso en Guadalajara», en Estudios Geográficos, $n^{\circ} 109$, pp. 499-559. Por nuestra parte, lo hemos estudiado en Alaejos y pueblos del Partido de Valdeguareña, ved: OJEDA NIETO, J. (1989): Alaejos, un pueblo de Castilla la Vieja en la España del siglo XVI, Valladolid, pp. 36-41; y (1997): Comendadores y vasallos (La Orden de San Juan y el Partido de Valdeguareña), Zamora, pp. 83-96.

4 A este respecto, recuérdese cómo CAXA DE LERUELA, M. (1631): Restauración de la abundancia de España. Nápoles, pássim, incide en el problema de las roturaciones.

5 Carta de Felipe II al Consejo de Castilla en 1572, en BIELZA, (1985), p. 99, citado por L. A. CÁNCER, L. A. (1999): La degradación y la protección del paisaje. Madrid, p. 28 nota 7. 
«E importa mucho la conservación de los montes ya que no hay lugar bueno sin ellos y también porque debemos conservarlos a los venideros, como los pasados los conservaron a los presentes» ${ }^{6}$.

\section{Localización del bosque de Orihuela}

Las fuentes no hacen referencia al bosque sino al monte. A lo sumo, e indirectamente, señalan los lugares donde hay árboles, con el fin de indicar las zonas a respetar; es decir, dónde no se debe practicar el carboneo, dónde no hay que talar o dónde extremar el cuidado con el fuego, incluso la prohibición absoluta. Con estas pistas y las proporcionadas por los apeos se puede ubicar la masa arbórea. Veámoslo:

En 1658 el Consell se dirige a S. M. solicitándole la prohibición de la tala de «pins verts ni sechs, ni fer carbo en los camps y terme de la p[rese]nt ciutat... desde lo Riu a la mar». La petición se fundamenta en los abusos que se vienen cometiendo, tema éste que analizaremos más adelante. La importancia del documento estriba en la localización de las zonas boscosas. Directamente cuando aclara adónde deben dirigirse los vecinos para satisfacer sus necesidades de leña y madera, que es tanto como decir dónde se hallan los bosques de Orihuela. A saber, en:

«lo camp de la Matansa, la Murada y Fondons ap[p]el[1]ats de Asp».

La otra zona de bosques se señala indirectamente, al describir los lugares donde se han producido cortes, talas, carboneo e incendios abusivos:

«Torre de Cascant y Torre de Mendo, Cañada Fonda, Cañada de Covatelles, Sant Ginés y cañada de les Estaques, Peña del Águila, Partida de Set Figueres en lo Plams de la Foradada, Cabeço Mortero, Font Siscar, Charco de la Gleda, Cañada Hermosa, Riu Sech, Alcarchofar, Partida del Ramblar, Pou del Rabat - y- Font Amarga».

En conclusión, los testimonios documentales — cartografiados esquemáticamente en el mapa adjunto — señalan dos zonas amplísimas y dispersas de arbolado: una, al parecer muy castigada, en la parte meridional; otra, al septentrión. Grandes superficies, evidentemente; mas en modo alguno merecedoras de la calificación de bosque-denso. Dominan amplios espacios abiertos. La lógica de los acontecimientos que no la fuentes explícitas dan la pista. En efecto, estas superficies, localizadas en los extremos más lejanos de la ciudad, correspondían, según el argot ganadero, con el «camp realech»; es decir, con la zona de terreno dedicada al pasto de los rebaños trashumantes. De tal modo que en los siglos XVI y XVII el vecino coetáneo, como el propio Consell, prefieren hablar de monte no de bosque. Y aún más explícitos, cuando han de referirse a esta zona, optan por emplear el término realengo.

6 Citado por ALONSO MILLÁN, J. (1995): Una tierra abierta. Materiales para una Historia Ecológica de España, Madrid, p. 161.

7 El documento añade otros lugares de dónde los vecinos pueden servirse: «Favanella, Fortuna e altres llochs aixi del Regne de Castella», que no pertenecen a Orihuela. Archivo Municipal de Orihuela (desde ahora A.M.O.), lib. 139, ff. 52v-53r. 
Figura 1. Bosque administrado por la ciudad de Orihuela, circa 1600.

(Sobre mapa actual del Bajo Segura)

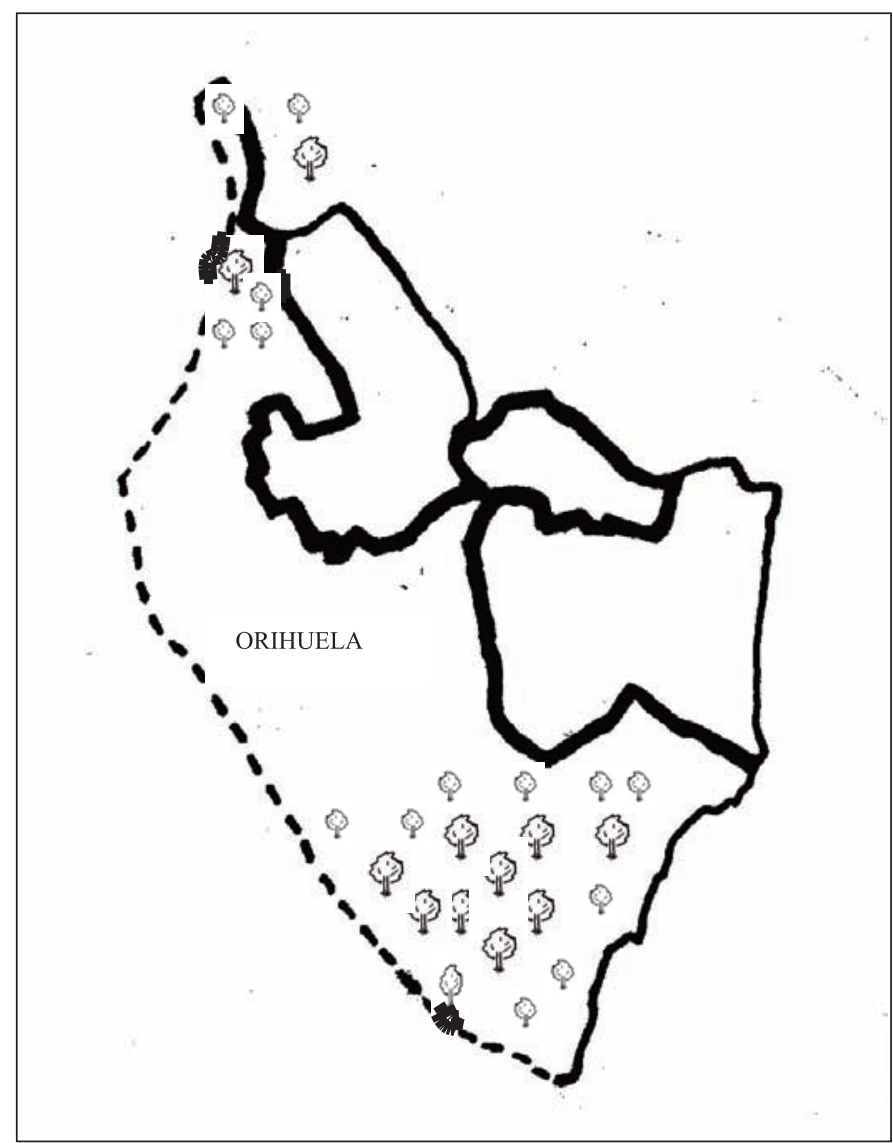

\section{Deslinde y configuración de los bosques}

En todo caso, el bosque como tal, es decir las zonas de arbolado que se extendían en manchas en los extremos del territorio de la ciudad, tenía un aprovechamiento mixto, de pasto y leña, difícil de compaginar. El Consell se decantó por lo primero, pues saca mucho de los arrendamientos ${ }^{8}$, al constituirse las rentas de las hierbas en una de las mayores partidas del presupuesto municipal ${ }^{9}$, siempre deficitario. En cambio, la leña y la madera, de disfrute comunal, no producía ingresos llamativos. Se dictaron sí, ordenanzas y normas adaptadas según las exigencias del momento para impedir el desbroce total, pero nunca el

8 El problema del déficit presupuestario llevaría al Consell a arrendar pastos que, a tenor de las ordenanzas primigenias, no eran arrendables sino de disfrute de los vecinos. Los diversos amojonamientos y deslindes llevados a cabo en el siglo XVII tienen como causa primera las quejas de los vecinos porque se estaban arrendando. 46-149

9 BERNABÉ GIL, D. (1989): Hacienda y mercado urbano en la Orihuela foral moderna, Alicante, pp. 
interés por el árbol fue comparable al del pasto $^{10}$. Pareciera que Orihuela solo defendía el árbol cuando sentía su necesidad, algo que notó muy pronto por otra parte, pues desde el siglo XV comienzan a verse claramente las restricciones a las talas y cortes no consentidos, publicándose las Ordenanzas que lo prohibían ${ }^{11}$.

Martínez Paterna ${ }^{12}$, pintando las excelencias de la Orihuela de las primeras décadas del diecisiete, da cuenta de la enorme variedad de árboles que cubrían riberas y bordes de caminos y veredas. Abundaban — dice_ olmos, álamos, chopos, fresnos, palmito, pinos, etc. Más lejos, las sierras se tapizaban de encinas, robles, carrascos, madroños y toda clase de pinos. El cronista se refiere a los primeros años de la centuria, cuando todavía no había llegado, aunque ya se presagiaban, los primeros síntomas de la recesión demográfica que habría de caracterizar el siglo XVII. Panorama idílico, que debe interpretarse con toda clase de cautelas. ¿Todo es fantasía? Evidentemente que no. En lo que al árbol se refiere, el cronista habló con certeza de la abundancia de los árboles de cultivo (moreras y otros). $\mathrm{Su}$ época es la de la seda, y la morera señorea la huerta y los caminos, como el álamo y el olmo las riberas, y el palmito el monte. Pero... encinas y carrascos y fresnos sería testimoniales. Y, por supuesto, nada de abundancia de madera, que los pinos — que son los más abundantes, como veremos enseguida- son raquíticos y de reducido porte. Pero al cabo, Martínez Paterna describió el paisaje de una época todavía poco castigada, porque lo años que restaban al Seiscientos introducirían nuevos cambios, haciéndole más desolador y menos arbóreo.

Y Cavanilles, pintando el paisaje de la Orihuela dieciochesca, matiza: «apenas hay árboles en dichos montes... ni en el citado [H]Urchillo, porque los vecinos los han ido cortando para leña, la qual es muy escasa actualmente, y por eso arrancan hasta las raíces de los arbustos». A situación tan calamitosa no se llega si no se viene arrastrando de tiempo atrás, porque el siglo XVIII, que indudablemente no cejó en su ataque al árbol ${ }^{13}$, no lo fue tanto como el anterior, pues en él las disposiciones y normativas en pro del árbol fueron más duras y rígidas; además de ser el siglo en el que se iniciaron las repoblaciones. Hecho éste que debe ser señalado porque marca — con clara divisoria- dos actitudes, dos formas de enfrentarse al problema: la defensa pasiva de la Naturaleza, del árbol más concretamente, y la activa, que se aproxima - pero sólo eso- a la ciencia ecológica. En los siglos XVI y XVII (por concretarnos en el presente análisis) se dictan normas en defensa de lo existente: que no se corte, que se tale en tal lugar, pódese a horca y pendón... En el XVIII surge la normativa positiva, que sin excluir la represiva, obliga a dar los siguientes pasos para poder talar:

10 BARRIO BARRIO, J. A. (1994): «La ganadería oriolana en el siglo XV: la regulación de los pastos», en Investigaciones Geográficas, núm. 12 , Alicante, pp. 247-254.

11 A.M.O., libs. capitulares de 1446 y 1454, citados con signatura antigua por A. NIETO FERNÁNDEZ, A.(1988): Orihuela en sus documentos, II. Economía y sociedad, siglo XIV-XIX. Agricultura, Ganadería, Industria y Comercio, Murcia, p. 65.

12 MARTÍNEZ PATERNA, F. (1632): «Historia/ de la/ Ciudad de Orihuela/ y de sus pueblos oritanos; tratase de/ su obispado, gobernación y/ baylía general; de los montes, de los ríos y/ fuentes e islas, de los promontorios, senos y puertos/ que tiene esta provincia», Orihuela, 39 fls., en VILAR, J. B. (1981): Orihuela, una ciudad valenciana en la España Moderna. Historia de la ciudad y obispado de Orihuela, IV, vol. III, pp. 857-876, concretamente 860 .

13 A este respecto, véase el informe de Francisco de Soto, del que extractamos algunas frases: «el Partido de la Asomada — en Campo de Salinas_- en otro tiempo frondoso, y hoy talado [...] el Partido de San Ginés... lleno de monte bajo..., pero lo restante muy destruido [...] La Horadada... sin monte alguno». Y lo mismo Rabate, Ciñuela, Tierras Nuevas, Torre Mendo. En situación parecida, se hallan los términos de La Murada y Barbarroja. Ved NIETO, A., ob. cit., pp. 68-69. 
FIGURA 2. Representación de los paisajes dominantes en Orihuela y Bajo Segura, circa 1600.

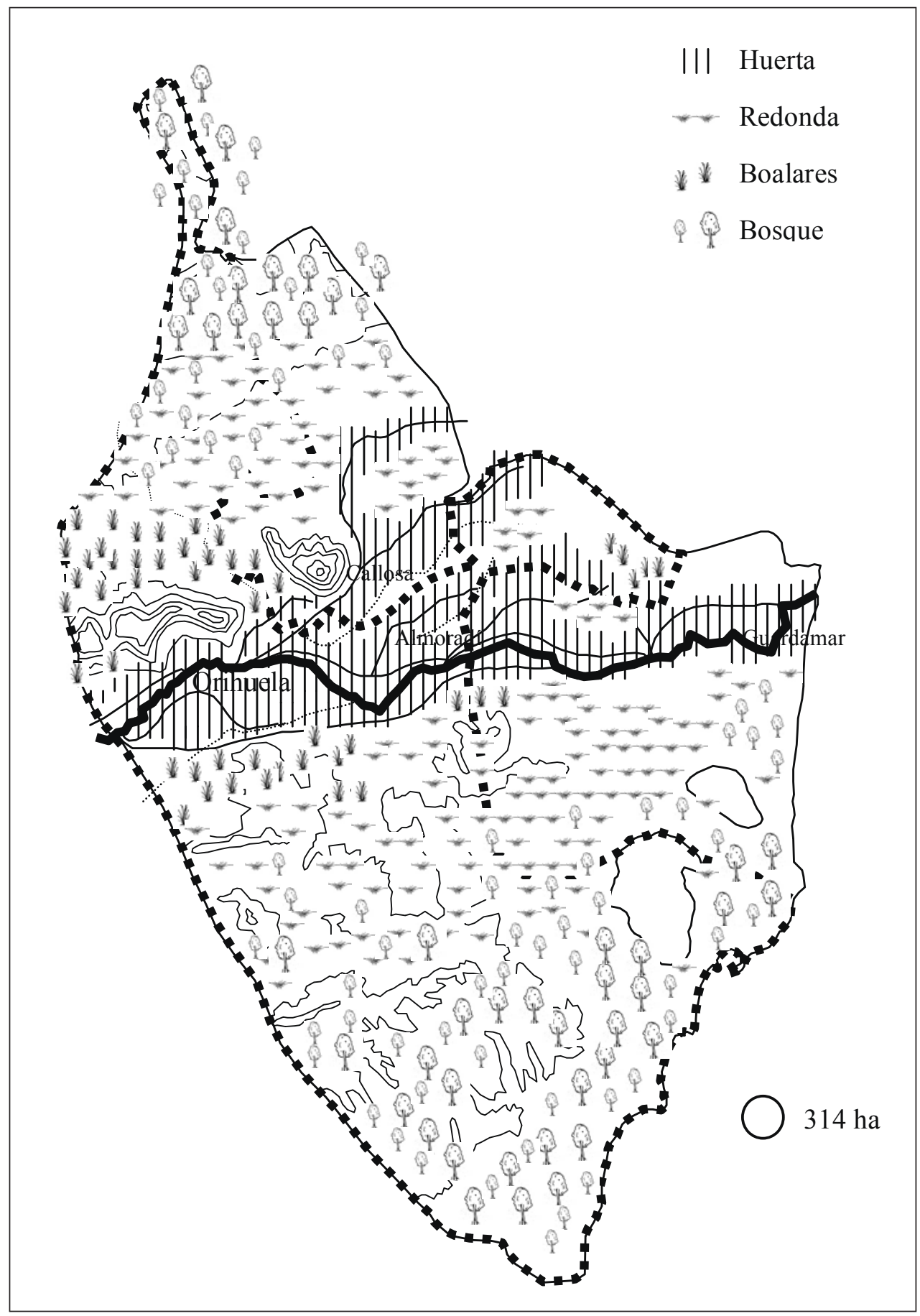


$1^{\circ}$ Fiscalización antes de otorgar el permiso de corte: «La ciudad acordó que el Caballero de la Sierra vea y reconozca los pinos —y señale sólo los que— hagan perjuisio» ${ }^{14}$.

$2^{\circ}$ Concesión del permiso a cambio de replantar: «Con la obligación... de haver de planttar tres por cada uno, de la misma especie, en la menguante de Luna del mes de enero... y de cuidarlos hasta esttar presos de dos [h]ojas» ${ }^{15}$.

Tabla 1

PROPUESTA DE DISTRIBUCIÓN DEL ESPACIO, CIRCA 1600

\begin{tabular}{|l|c|c|c|c|}
\cline { 2 - 5 } \multicolumn{1}{c|}{} & \multicolumn{2}{c|}{$\begin{array}{c}\text { TÉRMINO DE } \\
\text { ORIHUELA }\end{array}$} & \multicolumn{2}{c|}{$\begin{array}{c}\text { TÉRMINO DEL } \\
\text { BAJO SEGURA }\end{array}$} \\
\cline { 2 - 5 } \multicolumn{1}{c|}{} & Hectáreas & $\%$ & Hectáreas & $\%$ \\
\hline Huerta & 5.500 & 8,3 & 12.100 & 12,5 \\
\hline Boalares (Prados-carniceros) & 4.800 & 7,2 & 5.400 & 5,5 \\
\hline Redondas (Prados, dehesas y secano) & 15.400 & 23,3 & 32.700 & 33,6 \\
\hline Realengo (Prados y bosques) & 24.500 & 37,1 & 29.500 & 30,3 \\
\hline Marjales & 4.500 & 6,8 & 5.500 & 5,6 \\
\hline Salinas & 1.800 & 2,7 & 2.200 & 2,3 \\
\hline Resto & 9.500 & 14,4 & 9.700 & 10 \\
\hline
\end{tabular}

Nota: Cálculos de superficie obtenidos por proyección de los deslindes en planos y cotejo a través del SigPac.

Los datos no son más que una propuesta cuya interpretación ha de hacerse con toda cautela. En cualquier caso, el monte-bosque (Ved tabla 1) asentado en el realengo parece dominante y ocuparía más de un tercio del espacio administrado por la ciudad (37\%), y algo menos en la comarca (30\%). Sin embargo, no todo este espacio merecería calificarse de forestal, pues el aprovechamiento ganadero está también presente. A las redondas les ocurre algo similar, su explotación es mixta. El pastoreo las define, pero también el árbol campa esparcido, a modo de dehesas.

La conclusión es obvia: los siglos XVI y XVII, en Orihuela y su hinterland, configuran un paisaje no carente de arbolado, aunque el bosque es reducido y se ubica en puntos concretos (Ved figura 2). El árbol se halla por doquier, si por tal se incluyen los de la agricultura leñosa (moreras, sobre todo). Pero el bosque como tal; es decir, el espacio donde el árbol silvestre domina se localiza en dos zonas situadas en los extremos del campo de la ciudad, en los lugares más alejados. Una al Norte, de 7.000 ha, aproximadamente, lindando con los términos de Abanilla y Aspe (los Hondones). El pino — carrasco—, árbol dominante, se extiende por las laderas de la sierra, aclarándose en cotas altas. Bosque que tiene por enemigos no a los vecinos de Orihuela, sino a los de las poblaciones colindantes, los de Abanilla principalmente. Un bosque, en todo caso, con árboles de poco fuste y muy castigado.

En el extremo opuesto, en el triángulo formado por el mar, el límite con Murcia y la frontera con las redondas de Rabat, Alcachorfar, Font Amarga, etc., en el Sur del Bajo Segura, se localiza la zona más arbórea, cubriendo una extensión próxima a las 22.500

14 A.M.O., lib. 174, año 1716.

15 A.M.O., lib. 609, exp. 11, año 1763. 
ha. Los árboles son los mismos — pinos donseles y chaparros- y también de poco porte. Como zona, no obstante, más arbórea, provoca mayor atractivo entre los demandantes de leña y madera. No le andan a la zaga otros enemigos ya conocidos, los de Murcia y los foráneos que llegan por mar $^{16}$. Así que, en efecto, el campo del Sur, la zona de San Ginés más concretamente, el espacio sito en el triángulo delimitado, ofrece más posibilidades, mas por eso mismo está más castigado. Cortes, talas, carboneras e incendios, junto al ramoneo del ganado, se dan tanto en una zona como en la otra, pero en modo alguno comparables. El Sur estará sometido al ataque continuo, hasta el extremo de llegar a situaciones inadmisibles e irreversibles, lo que obligará al Consell a vedar el disfrute de madera y leña durante ciertas temporadas.

\section{Cortes y talas abusivas}

La normativa en defensa del bosque se incentiva a finales del siglo XV. Normas acordes con la legislación superior, que cayeron en saco roto o bien surtieron poco efecto, porque lo cierto es que durante la primera mitad del XVI el Consell no puso empeño en hacerlas cumplir. Su actitud solo cambiará cuando tenga constancia de la mengua del árbol, y eso no sucederá hasta entrada la segunda mitad, cuando se produzca el boom demográfico, no sólo en Orihuela sino en toda la comarca y pueblos colindantes. En este momento comenzarán a llegar las quejas, y será en este momento también cuando el Consell pase a la acción, obligado además por la preocupación de los vecinos por los precios de la leña y la madera.

El primer caso de actuación solicitado por los propios vecinos se constata en 1550, cuando los herreros se quejan de que el carbón está subiendo de precio a causa de que los carboneros no lo venden directamente sino a los revenedors, que más tarde lo revenden a mayor precio. Y siendo así que el carbón se hace con leña del común, ¿cómo es que el Consell —se preguntan los herreros - no controla los precios? En vista del desinterés deciden intervenir: nombran un procurador y le encargan que intervenga ante el Consell, pues piensan que no es «conforme a les costums de la p[rese]nt ciutat e dels dits sos offiçis» ${ }^{17}$, que el gobierno no tome cartas en el asunto. Actuar contra leñadores es obligación del Consell. Pero se presenta un problema que puede resultar contradictorio. Porque en el término de Orihuela hay espacios realengos, y aquí su control no es total, además de hallarse lejanos. En cambio, sí posee facultad para decidir qué y quién corta sobre el resto del término, como bien claro lo dejó manifiesto en la crida del 18 de julio de 1561:

«manant a tot hom en $\mathrm{g}[\mathrm{e}] \mathrm{n}[\mathrm{e}] \mathrm{ral}$ y a cascu en especial... sien vehins o forasters... que ni[n]gu[n] sia osat de fer talladura ne tallar pins ne azembuigs ne altre qualsevol sort de arbres situats en lo camp de dita ciutat pera fer carbo sens expresa llisensia e facultat de Ses Mag[nifich]s $»^{18}$.

El pregón de 1561 saca a relucir el problema. El Consell publica que sus atribuciones alcanzan al «camp de dita ciutat»; y esto es precisamente lo que se cuestiona. ¿Hasta dónde llegan sus atribuciones?: ¿A todo el campo?, ¿también al realengo? De las dudas sacan

16 Los testimonios lo relatan con detalle. En 1583, por ejemplo, se descubre un corte ilegal y tras seguir «les carritades... ques de carro - llegan - prop del aygua de la mar», donde hallarán 180 pinos prestos a ser embarcados. A.M.O., lib. D-2.236, ff. 119r-125r.

17 Archivo Histórico de Orihuela (desde ahora A.H.O.), Protocolo, lib. 190, s/f., 18 octubre.

18 A.M.O., lib. D-2.225, ff. 86r-106r. Crida inserta en testimonio del año 1580. 
partido los oligarcas, que ven las posibilidades de aprovecharse de la confusión. Por esta razón, el gobierno municipal buscaría un permiso real que precisase su autoridad. Por lo tanto, el motivo principal no es tanto parálisis cuanto indefinición de poderes. Hubo que esperar al Privilegio Real, que llegó en 1569, para intervenir en los bosques. Desde este instante, el poder abarcaría a todo el «camp» y no solo al «camp de la ciutat», y así lo recordaría constantemente:

«ni sien osats... ne permetre que es tallen pins alguns en el camp per a fer carbo ne altre qualsevol efecte si no es presehent llicencia de Ses Mag[nifich]s» ${ }^{19}$.

Conseguido el permiso, al Consell le faltaría tiempo para buscar a los malhechores. Eleva las penas: en 1561 era de 60 sueldos y pérdida del carbón, en 1569 son ya 100 libras, o sea nada menos que 2.000 sueldos; por eso, pasará a la acción inmediatamente. El mismo año encarcelará a unos pastores que habían talado varios pinos para el redil. A partir de aquí incrementará la actividad fiscalizadora (o quizá habría que decir que las fuentes son más explícitas). Es el caso que en el último tercio del siglo XVI se acentuará la vigilancia en aquellos pagos por donde actúan los vecinos foráneos, sobre todo murcianos. La lejanía de la ciudad impulsaba a las poblaciones limítrofes a buscar leña en los montes de Orihuela. Pero de algo habrían de servir — aunque no siempre - la vigilancia del Caballero de la Sierra y la de los propios vecinos, interesados en que murcianos y pastores trashumantes no agostasen más sus menguadas fuentes de leña y madera. Los documentos dan fe de cómo, cuando hay interés, no se pierde tiempo en preparar la cuadrilla para perseguir a los malhechores, una vez que las noticias llegan al Consell.

Un caso habla por todos. Nos encontramos en marzo de 1580, cuando llegan avisos de que «certs particulars de la ciutat de Murcia estan fem carbo en lo terme de la p[rese]nt ciutat en lo pou de les Set Figueres, lo qual carbo lleve[n] a la dita ciutat de Murçia». Noticia que confirma que los murcianos se han aprovechado del movimiento de personas y ganado porque en este momento «los ganaders que estan ygualats en la Redonda estan de partida». Al instante, el Consell comisiona al Justicia para que acuda «al lloch hon estan dits carboners de Murçia e mane pendre aquells y lo dit carbo... y als dits carboners mane portar presos a les presons comunes».

El asunto es grave, porque la persecución, iniciada el 14 de marzo, no había finalizado todavía el 24. Este día, recorriendo el borde de ambas poblaciones - Murcia y Orihuela-, el Justicia dará con los carboneros:

«en la canyada vulgarment dita de les Contiendes en la vertent e terme de la p[rese]nt ciutat..., en la partida dels Plans de la Foradada deves lo pou de les Set Figures — donde - fonch atrobat un home... cremant un forn de carbo - y otro en- Alcarchofeta - y otro más a- un tir de alcabus del aygua de la mar» ${ }^{20}$.

No basta, empero, una autorización, por muy real que sea, para paralizar una necesidad. Cortes y talas seguirán porque siguen las necesidades. Unos legales, aquellos que tengan el permiso o se atengan a la normativa vigente, porque evidentemente los vecinos precisan

19 A.M.O., lib. D-2.227bis, ff. 73v-74r. Privilegio firmado en Aranjuez el 23 de noviembre.

20 A.M.O., lib. D-2.225, ff. 86 r-106 r. La prisión de los cuatro carboneros traerá cola: primero, porque se escaparán de la cárcel — «foradare[n] una paret de les dites presons»—; y segundo, porque los carboneros, una vez en Murcia, alegarán que ellos se servían de la leña recogida en la vertiente de la cañada de las Contiendas (obsérvese el nombre) del lado de Murcia, no de Orihuela. 
leña para la cocina, para la construcción, etc.; y otros ilegales, sin autorización. Dar con los infractores no es fácil, pues depende no sólo de que sean vistos, sino de que alguien ponga una reclamación; dicho de manera contemporánea: clame — ponga «clam»— ante el Consell. De ahí que las fuentes escaseen al respecto, incluso que no generen documentos. No obstante — como tendremos ocasión de ver-, las irregularidades se perciben a través de las normas, pues insisten constantemente en la prohibición de talas o expresan con diafanidad cómo deben ser podados los árboles.

Son, pues, los grandes destrozos los que han originado fuentes documentales de primer orden; porque en la mayoría de los casos ocasionaron gastos, se ajustaron a derecho... y terminaron en pleito. A tenor de los informes, la zona más castigada, el bosque con mayor presión, coincide con el más lejano, el situado en la zona sur, desde «Camp de les Salines» hasta «los Plans de la Foradada». La lejanía de la ciudad y la proximidad al mar facilitaba la huída de leñadores y carboneros, y, cómo no, la fácil extracción de la madera o carbón. Por eso había que andar ojo avizor, pues talas de grandes proporciones y carboneras ilegales no faltaban ${ }^{21}$.

Por lo general, al informar sobre las talas de árboles, se tiende a generalizar — se talaron «molts pins», se dice-, mas en ocasiones se precisa — «a son parexer seran mes de tresçents vints (...), pasarien de cinch cents pins»—22. En cualquier caso, los infractores se defenderán: si cortaron —dirán— es porque primero han «obtengut lliçençies...fermades dels señors jurats» ${ }^{23}$. Habrá quien utilice la necesidad como argumento, porque ¿qué le queda al vecino que en momento de crisis agraria no encuentra trabajo?: José Vernícola y Blas Moñino, que fueron hallados haciendo carbón en Fuente Amarga «en un cabeso appellat Pu Jalvares», adjuntarán en su defensa que lo hacían por «un tros de pa perque no trobaven en que treballar pera poderse sustentar» ${ }^{24}$.

Que las mayores actuaciones se desencadenaran en el zona meridional del campo de la ciudad no quiere decir que se despreocuparan del resto. Es cierto que la documentación aporta menos casos del bosque septentrional, pero no ha de interpretarse salva de madereros y carboneros. También allí se cometían atropellos. Algunos, como el ocurrido en días precedentes al 11 de febrero de 1672, con claro síntoma deforestador, pues fue de tal calibre que el Caballero de la Sierra, tras dar el anuncio y poner el «clam» correspondiente, hubo de acudir al lugar de autos — «al Fondo appellat dels Frares del Colegi de Predicadors»— con escribano, «verguer y altres gents» para verificar la

«gran quemada de pins, romeros y aiximateix — la - gran tala de pins verts tallats per lo peu y molts de aquells pelats en forma de rollisos y altres trosetats... pera armar carboneres» ${ }^{25}$.

21 «Fran[cis]co Hernández acussa y possa clam de (...) Escalona p[er]que a cremat un forn de carbo». A.M.O., lib. D-2.237, f. 279r., año 1595.

22 A.M.O., lib. 312, ff. 146r-155v., año 1678.

23 A.M.O., lib. D-2.262, ff. 202v-203r., año 1625.

24 La justicia no tuvo en cuenta la razones y ambos serían condenados, aunque no se podrán proceder contra ellos porque se escaparon. A.M.O., lib. D-1.415, ff. 325r-345v., año 1646.

25 La información llevada a cabo descubrirá a los autores: todos vecinos de La Granja. A.M.O., lib. 305, ff. 6r-9v., año 1672 . 
Diversos autores han analizado la ocupación —ilegal, pero luego legalizada (no se olvide que controlan el Consell) — de redondas y realengo por oligarcas y señores ${ }^{26}$. Eran ocupaciones que buscaban la puesta en explotación de cañadas para, posteriormente, por la política de hechos consumados, conseguir la propiedad y aumentar su patrimonio. En un futuro inmediato el incremento patrimonial lo utilizarán para obtener el señorío y, más tarde, el título nobiliario ${ }^{27}$. A lo que viene al caso, lo importante de este proceso de colonización era la labor de deforestación que llevaban a cabo. Se aprovechaban de la necesidad de carbón de la ciudad. Y, en efecto, concederán permiso, y aun ordenarán, cortes y talas, como por ejemplo el permiso de don Enrique de Rocafull y Peñaranda, que

«com a señor directe que es de la s[eñorí]a de Molina, orta de la p[rese]nt ciu[ta]t... dona llisencia, permis y facultat a mossen Francisco de Ochoa, prevere y beneficiat del hospital del Corpus, pera que sens encorrer en pena alguna puxa tallar les arbres... en la sua heretat subjeta a dita señoria» ${ }^{28}$.

Entonces se producirá el choque entre Consell y señores. Choques falsos en muchas ocasiones, pues no se olvide cómo el primero está dominado por los segundos; mas cuando afectaba al campo realengo se producían fuertes enfrentamientos. Cuando los carboneros, presionados por los justicias, se vean en la tesitura de defenderse, descubrirán las verdaderas razones, que no son otras que las licencias de los señores:

«... les moltes tales que es fan en los pins dels camps de la p[rese]nt ciutat pera fer carbo — se hace, dicen — so color de que tendrien lliçençia de alguns señors de cañadas» ${ }^{29}$.

El Consell combatió - ya se ha indicado hasta qué punto- las intromisiones de los señores; pero no acabaría con ellas. De vez en cuando surgen testimonios de carboneros que justificarán su acción no ya en base a alguna licencia sino a orden expresa. Éste sería el caso de aquellos más de 500 pinos talados en «cañada Fonda». Según los carboneros cortaron en las propiedades y por orden de don José Roca de Togores, quien mandó «fer unes carboneres pera fer carbo tots los dits pins». Con toda certeza fue orden emanada de Roca de Togores y no simple licencia. Los leñadores lo demostrarán presentando el jornal por el que habían sido contratados: 4 reales al día ${ }^{30}$. Así pues, los señores intentan expandir su propiedad a base de ocupaciones y roturaciones. Y las talas de árboles marcan el inicio de la invasión. Consciente de este proceso, el gobierno municipal sale en defensa del bosque haciendo valer el Privilegio Real —de 1569 - para evitar el «dany del comu» ${ }^{31}$.

26 BERNABÉ GIL, D. (1983): «La Vega Baja del Segura en vísperas de la expulsión de los moriscos: estructura de la propiedad de la tierra», en Estructuras y regímenes de tenencia de la tierra en España, Ministerio de Agricultura, Pesca y Alimentación, serie Estudios, pp. 61-74. Del mismo, (1999-99): «Insalubridad y bonificaciones de almarjales en el Bajo Segura antes de las Pías Fundaciones de Belluga», en Revista de Historia Moderna, $\mathrm{n}^{\circ}$ 17, Alicante, pp. 45-72.

27 GIL OLCINA, A. y CANALES MARTÍNEZ, G. (1988): Residuos de propiedad señorial en España. Perduración y ocaso en el Bajo Segura. Alicante, pássim. MATEO RIPIO, V. (1994): Oligarquía y poder en el siglo XVIII. Alicante, pássim. D. BERNABÉ GIL, obs. cits.

28 A.H.O., Protocolo, lib. 480, s/f, 8 de julio de 1620.

29 A.M.O., lib. 134, ff. 62r-63r., año 1654.

30 A.M.O., lib. 312, ff. 148r-155v., año 1678.

31 A.M.O., lib. 134, ff. 62r-63r., año 1654. 
La defensa de lo comunal, he aquí la clave para entender el alcance del poder municipal frente a los abusos. El bosque, sito, como se ha visto, en su mayor parte en terrenos realengos y concejiles es de aprovechamiento comunal: todo el pueblo puede gozar del árbol, respetando, obvio, normas y ordenanzas. Y los munícipes deben, en buena lógica, interesarse porque sea así; pero antes que nada han de poner los medios, y aun los remedios, para preservarlo.

\section{Incendios y despropósitos}

Un incendio, natural o provocado, en campo despoblado podía extenderse con suma facilidad y arrasar todo el arbolado. Había, pues, que extremar las precauciones; de aquí la vigilancia del Caballero de la Sierra y las normas estrictas a los carboneros limitando el uso del fuego. Pero... los incendios son inevitables ${ }^{32}$. La propia Naturaleza los provoca y los más (o quizá las fuentes fueron explícitas en estos y no en aquellos) los causa el propio vecino, el carbonero especialmente.

En todo caso, incendios hubo, e incendios graves y provocados. Los textos, adelantándose a los informes periodísticos, los describen con exactitud, pormenorizando todos los detalles. Oigamos el informe levantado tras el anuncio de Gabriel Román y otros trabajadores, que el 13 de septiembre de 1603

«arranca[n]t barrella encima la canyada de les Covatells... veron q[ue] en la canyada - había un fuego- molt gran en los pinars de dita canyada... en ves Sanct Gines y la penya del Águila».

Tras el aviso, el Consell mandaría inspeccionar el desastre y dar con el infractor. A través del informe se sigue el camino de las llamas. Se iniciaron

«en la partida del pou de les Set Figueres — y después de- aver abrasat y cremat tot lo camp que y a, desde dita partida - avanzó- fins la penya del Águila y aygua de Sanct Ginés —orientándose- fins lo cabeço del Mortero, Caseta Blanca y Font del Siscar».

Fuego enorme que arrasaría «pins y azembuchs en largaria y amplaria pus de tres llegues... causa[n]t grandissimi e quasi innumerable dany». El desastre estaba hecho; pero ¿quién había sido el causante? El Justicia Criminal acusaría a Pedro Almodóvar, huido; le embargaría los bienes y dictaría orden de que fuera hecho «pres y capturat y possa[n]t en les presons comunes» ${ }^{33}$. El incendio de 1603 no sería el único caso. Se conocen los de 1620, 1658, 1660, 1681, etc. En 1658 se constatan dos al menos, y de considerables proporciones el primero pues quemó más de media legua. Pero lo grave es que incidieron en el mismo lugar: la zona de San Ginés. Para el Consell, los incendios eran provocados. Por eso, siempre que recibía noticias de un desastre de esta naturaleza, nombraba una comisión

32 Sabemos, a través de las fuentes, que ya entonces se tenía por costumbre la quema de los rastrojos. Algo que inexorablemente causaría incendios en algún descuido. Al menos, en lo que toca a daños particulares, puede verse el concierto entre Juan Colón y Jaime Ruiz por causa de que los hijos del primero «cremant los seus rastollos de la sua heretat questa situada en la orta... partida de la Alquibla an cremat algunes rames de les moreres». Más grave fue el daño causado a otro vecino, que le afectó en el trigo y la cebada. A.H.O., Protocolos, lib. 262, s/f., 17 de agosto de 1580, y lib. 379, s/f., 27 de agosto, respectivamente.

33 A.M.O., lib. D-2.236bis, ff. 283r-288v. 
encargada de dar con el pirómano: «importa fer averiguaçio de les persones que hauran fets dits cremats pera que sien punits» ${ }^{34}$.

Tiene, con los incendios, mala experiencia, pues ha constatado que la mayoría son intencionados. Que sea así entra dentro de la lógica de los acontecimientos. Durante el siglo XVI, talas, cortes e invasiones de señores han reducido la zona arbolada. Pasado el declive demográfico de mediados del XVII, e iniciada la recuperación, el bosque vuelve a atraer a los carboneros, incentivados por la demanda. La consecuencia no se hace esperar: éstos provocan incendios parar utilizar la leña quemada en sus carboneras. Lo explica el Consell: procuran hacer «insendis cascun dia sols pera dit effecte de tallar leña y fer carbo» ${ }^{35}$. Pero es que además, los carboneros se ensañaron con una zona concreta, la más lejana, la meridional, el campo — conocido contemporáneamente - como de San Ginés. Incendio tras incendio, tala tras tala... el campo de San Ginés sería uno de los más castigados. Llegó un momento en que el propio Consell dio la voz de alarma: San Ginés se quedaba sin árboles. Asustado, solicitó del Rey —7 de septiembre de 1658 - permiso para prohibir cualquier tala de cualquier árbol, fueren «pins verts, ni sechs, ni fer carbo en los camps y terme de la p[rese]nt ciutat —ni en las dehesas y cañadas de particulares (entre líneas) — desde el riu a la mar per temps de deu anys». Se solicitaba la capacidad de imponer fuertes sanciones: «fins a mort inclusive».

Incendios, talas y carboneo terminaron por llevar al bosque meridional a una situación límite. Los munícipes, conscientes del grave deterioro, endurecieron las penas: Primero, solicitaron la pena de muerte; en segundo lugar, extremaron la vigilancia ${ }^{36}$, multiplicando las actuaciones del Caballero de la Sierra; y por último, solicitaron del Rey una medida drástica: paralizar cualquier tipo de corte, tala o carboneo en la zona sur. Justificarían la petición exponiendo la grave situación en la que se hallaba esta área boscosa. Mas conociendo las necesidades del pueblo, en la petición no olvidaron precisar adónde habrían de acudir los vecinos para hacer acopio de leña y madera. Es en este momento, 1658, cuando el Consell diferenció y marcó con nitidez las dos zonas que se han venido señalando: la meridional, degradada, y la septentrional, con mayores posibilidades.

Pero el permiso de 1658 redujo las intenciones restrictivas del gobierno: solo una parte de esa amplia zona que comprendía las tierras realengas quedaría salvaguardada de cortes y talas. Sería la parte más castigada, la que en tiempos había estado más poblada de árboles, pero también porque dentro de ella se hallaba el convento-ermita de San Ginés ${ }^{37}$. Había que

34 A.M.O., lib. 141, ff. 126v-127r., año 1660.

35 A.M.O., lib. 139, ff. 52v-53r., año 1658.

36 Los testimonios documentales son frecuentes, incrementándose a partir del último tercio del siglo XVII, pues por el aumento de población se incrementa la demanda de leña y madera. De aquí que «ynporta fer averiguaçio - constantemente- de les persones que hauran fets dits cremats pera que sien punits». Incluso el virrey de Valencia ordenaría extremar la vigilancia. Así, a modo de ejemplo, el 20 de noviembre de 1681 llegaría la orden de «veure los cremats y tales de pins verts en les cañades del capita Pere Liminiana y [H]urtado, sitas próximas al mar y hacia las torres de la Horadada y Cabo Roig». A.M.O., lib.141, ff. 126v-127r., año 1660 y lib. 152, ff. $173 \mathrm{v}-174 \mathrm{v}$. , respectivamente.

37 La razón de ser, a tenor de «Jaume Serra — que escribirá una-Memoria de la Antiguitat de la Torre y cassa de S[en]t Gines», fue la torre para defensa de los vecinos levantada en «lo Riu de Climent que huy es diu de Sent Gines». Más tarde la cofradía edificaría una ermita junto la torre, y por último, en 1440, el Consell fijaría los límites. A.M.O., lib. 114, ff. 104r-107v. 
protegerle, además de ayudarle ${ }^{38}$, porque se había constituido en bastión ante los ataques esporádicos, pero frecuentes, de piratas berberiscos ${ }^{39}$.

Razones que explican los constantes cambios de una orden a $\operatorname{otra}^{40}$. El bosque que le rodeaba, no obstante, le daba cierta seguridad y le ayudaba a mantenerse, aportando, gracias al pasto y los beneficios de la leña y carbón, el atractivo que le faltaba. Se pretendían evitar los incendios provocados.

Una de las razones de esta mayor vigilancia y precaución se encuentra en la defensa del patrimonio del convento-ermita, uno de los principales atractivos para incentivar el asentamiento de las congregaciones religiosas, poco dadas a aventurarse en terrenos inhóspitos y peligrosos $^{41}$. Por otra parte, los monjes que lo habitaron a lo largo de ambas centurias (siglos XVI y XVII) no parece que se mostrasen muy respetuosos con los árboles. Cortaban para ellos, concedían permisos a terceros y al abandonar el convento lo dejaban, si no esquilmado, en situación deplorable, lo que añadía un nuevo escollo al futuro establecimiento. Al Consell no se le escapaba esta situación, por eso aplicaba también las normas a los frailes ${ }^{42}$.

Las tensiones entre frailes y gobierno municipal afloraban en este punto. Por un lado, el Consell atraía a las congregaciones ofertándolas el convento-ermita con el uso y disfrute del bosque — pasto y leña — que le rodeaba (además de la ayuda para el mantenimiento del edificio); pero, por otro, limitaba los abusos. Los frailes, empero, hacían oídos sordos a las prohibiciones y alegaban que en el momento del establecimiento se les había concedido los derechos

«de fer y manar fer carbo — en cañadas - desde lo dit convent fins al mar y tallant y fent tallar pera dit efecte de fer carbo tots les pins y altres arbres que y a... y aixi mateix pera altres effectes y ussos de dit convent ${ }^{43}$.

Pero no todo son rencillas. En ocasiones, ambos — munícipes y frailes- defienden el patrimonio del convento. Claro está que esto es así cuando es un tercero el infractor. En este caso los frailes se convierten en los mejores guardianes de San Ginés. Veamos un suceso: En 1686, ocupado por los carmelitas, los monjes anuncian que «se ha fet una tala de pins en lo terme de S[en]t Gines — cuando, según el Cap. 9 del acta de establecimiento- esta prohibit taller ningun pi». Averiguado el asunto, se expropia el carbón; pero, he aquí el interés, el Prior del Convento «de S[en]t Pau, orden de Nostra Señora del Carmen», consigue que la leña cortada se use para carbón y que los beneficios reviertan en la obra del convento ${ }^{44}$.

38 En 1474 se le concede el derecho de peso «hon se pesen les mercaderies, carbo e altres coses... p[er]a la casa ho ermita del glorios Sent Gines del riu Climent... p[er]a reparasio de la dita casa e obra de aquella». A.M.O., lib. 32, f. 27.

39 En 1555 el convento se donó a los franciscanos, pero cautivados se transfirió primero a los frailes de Santo Domingo y luego a los mercedarios. El relato corresponde a «Jaume Serra», según la Memoria citada, f. 104.

40 La entrega a los mercedarios en A.M.O., lib. 68, f. 139, año 1555. La donación del «convent de N[ost]ra S[enyo]ra de Viaseli y Sent Gines de Oriola... a la religio de la Cartuxa», en ibídem, lib. 125, ff. 223-240. Para otras donaciones ved la Memoria de Jaime Sierra, supra. Asimismo, en A.H.O, Protocolo, lib. 23, s/f, 17 de enero de 1497, se cita la reunión de los 23 cofrades para admitir a los franciscanos.

41 Los testimonios son numerosísimos. Pueden verse en A.M.O. libs. 162, 135, 586, 145..., de 1644, 1655 , $1661,1667 \ldots$, respectivamente.

42 «cave veure y regonexer lo convent de S[en]t Gines pera saber en quin estat esta despues que lo han dexat els monges de la Cartuxa». A.M.O., lib. 142, ff. 27v-28v., año 1663.

43 A.M.O., lib. 82, exp. 22, f. 4 r., año 1666.

44 A.M.O., lib. 156, ff. 254r-255r. 
¿Mas de qué sirven todos los cuidados si al final se toma una decisión contraria a lo que se ha venido defendiendo? A finales del siglo XVII, cuando cabía suponer una reforestación gracias a la vigilancia y cuidado de años precedentes, el gobierno municipal otorga licencia a don Alonso Banega (o Fanegas) para instalar «un forn de fer vidre» en la partida o campo de San Ginés. La concesión ${ }^{45}$, del 28 de septiembre de 1693, tendrá efectos devastadores para el pinar que tanto había costado rehacer. Tras el permiso, confirmado el 19 de octubre de 1696, una vez que el propietario hubo levantado «dos palaus y una barraca pera la habitaçio de la gent que ha de treballar en dit forn», se iniciaría la fabricación de vidrio. Se impusieron dos condiciones: abastecer a la ciudad con vidrio de calidad y no perjudicar el pinar. Pues bien, ni una ni otra ${ }^{46}$. Los resultados, un fracaso mercantil y un desastre ecológico.

En 1703, a tan solo 7 años de la confirmación, a diez de la concesión, el Consell obligó al propietario a cerrar la fábrica ${ }^{47}$. Las esperanzas depositadas en don Alonso habían fracasado. No sólo no pudo competir con el vidrio foráneo en calidad y precio, sino que la segunda condición —no perjudicar el pinar— tampoco la cumplió. Es más, se causó un desastre de enorme envergadura. El testimonio documental lo señaló claramente: «en lo de la partida de Sent Gines hon al present esta — el horno- se ha consumit tot lo Pinar que hi havia per haverse tallat pera alimentar dit forn». Un desastre mayúsculo que, a tenor de los regidores, había que frenar antes de que «acabara — con- la leña que se precisa pera el consumo dels vehyns» ${ }^{48}$.

\section{Ordenanzas y normas en pro del bosque}

Los ataques al árbol, además de perjudicar al vecino por restringirle la capacidad de disfrute, acaba con los beneficios que la explotación silvícola reporta al Consell. Las consecuencias lógicas ante tanto desmán serían extremar la vigilancia, esmerarse en el cuidado y reglamentar unas normas protectoras. En una palabra: controlar. Controlar cortes y talas, controlar podas, controlar a pirómanos... y controlar el comercio de la madera, la leña y el carbón.

Desde tiempos remotos dos normas, al parecer consuetudinarias, se acaban imponiendo en el medioevo: evitar, primero, la tala del árbol; y segundo, cortar las ramas con cierto orden, no de cualesquier modo, sino a horca y pendón. La ley $7^{\mathrm{a}}$ de 1496 —Cortes de Burgos de 26 de octubre - reguló lo que de hecho se venía haciendo sobre las podas de los árboles. La ley, explicada en los manuales agrícolas contemporáneos ${ }^{49}$, en modo alguno podía calificarse de novedosa, más bien convirtió lo que fuera costumbre en norma legal. Desde finales del siglo XV, y a lo largo de todo el XVI, los gobiernos municipales harán suyas la legislación emanada de las Cortes, ajustando la normativa propia a la nacional. La poda y el corte de ramas a horca y pendón es paradigmático. Sin saber su origen — seguramente procede de la praxis agrícola- se transmitirá generación tras generación hasta pasar a ser de uso común. Las Cortes lo harían suyo, y de aquí — sin que sea éste el camino de todos

45 La fecha procede del documento de 1703; sin embargo el Libro Capitular apunta la concesión en 1694. Ved A.M.O., libs. 161 y 165, ff. 121r-122v y 109r-v, respectivamente.

46 Con respecto a la primera condición, el Consell, al retirar el permiso aclararía que el vidrio de fuera «el donen mes barato - y- de millor calitat». A.M.O., lib. 165, f. 109r.

47 A.M.O., lib. 165, f. 109r-v.

48 Ídem.

49 Horca — Ved COVARRUBIAS, S.: Tesoro de la Lengua Castellana, pp. 698-699— «en rigor es una percha, que al cabo se remata en dos gajos». Y el Diccionario de Autoridades explica la poda de horca y pendón como la técnica consistente en dejar «que en los árboles mayores se dexe el tronco con dos ramas». 
los municipios - a las ordenanzas municipales. Orihuela no fue una excepción, asumió la ley y la incorporó a sus ordenanzas junto a otras del mismo fin.

A finales del quince y a lo largo de dieciséis el problema del bosque de Orihuela no era la poda o corte de ramas, sino la tala abusiva para el carboneo. En consecuencia, las normas insisten en estos puntos: «que nengu no sia gosat fer carbo..., no sia gosat de merçe foch ${ }^{50}$. En las postrimerías del Quinientos se incentivan los desmanes y los abusos; es entonces cuando además de insistir en las anteriores normas se veda la tala en determinados lugares. Los vecinos, con dificultades de aprovisionamiento, buscan leña en las ramas, extralimitándose en los cortes. El Consell se ve obligado a recordar privilegios y estatutos: no corten — dirá- sino «deixant en aquell (el pino) forca, eo rama, pendo e guia». En el siglo XVII ha de recordarlo constantemente; incluso al dar el permiso a los carboneros debe insistir en que corten: «dexant pendo y guia (...), dexant guia o pendo en la forca dels pins $»^{51}$. Retahíla calcada, ciertamente, pero una prueba más de la falta de leña, que hace incumplir la norma al vecino, siempre propenso a cortar más de lo que debe.

Como la leña y la madera escaseaban hubo de acentuarse la vigilancia y el cuidado. Se acudió entonces a la prohibición total. Cuando tras los desastrosos incendios y el excesivo carboneo del Seiscientos el bosque camine hacia una situación insostenible, no quedará más remedio que limitar los cortes. Se exigirá la autorización expresa del gobierno municipal, de todo el Consell no de un Justicia o Jurado. Y esta medida afectará a todos. De hecho, la ordenanza que reguló el uso y disfrute del bosque, se había ido perfilando con el paso del tiempo, aunando leyes reales y estatutos de la ciudad. Así, a las ordenanzas de 1494, cuyo punto de interés es más la huerta que el monte ${ }^{52}$, se suman las leyes reales de 1496 que regulan el corte y la poda de ramas. Después llegarían las ordenanzas de 1548 insistiendo en el cuidado y precaución con el fuego ${ }^{53}$. El «Privilegi del Nou Regiment» de 1569, concedido por Felipe II el 23 de noviembre de 1568, dará fuerza al Consell al conferirle la potestad plena sobre el bosque y el árbol. Guinart - y Ocaña ${ }^{54}$ - , tras la revisión de las ordenanzas de la ciudad, hecha en 1625, lo incluiría en el Estatuto 40, dejando definido con toda claridad los procedimientos de uso y disfrute del bosque. Con posterioridad, en 1702, el recopilador Tomás Martínez, lo copiaría al pie de la letra en el Cap. XXI, punto 6, bajo el epígrafe: «Sobre tala de pinos». No debe olvidarse, empero, que los puntos clave —normas de corte y tala, así como permisos del Consell— procedían del Privilegio de 1569. Eso sí, se añadiría la exigencia de que el permiso fuese otorgado por el Consell y no de modo individual por sus componentes. En resumen, el Estatuto 40, que trata de frenar «lo notable dany, è perjuhi ques causa, $y$ fa en los monts, $y$ tales de pins», establece ${ }^{55}$ :

$1^{\circ}$ Que ni justicias ni jurados «donen licencia per scrits, ni de paraula à persona alguna, Colegi, ni Universitat pera que puga talar pins de peu pera fer leña y carbó[n]».

$2^{\circ}$ Que «sols puguen donar licencia los dits Jurats conciliarment ajustats en sitiada» convocada oficialmente y con el escribano de la Sala.

$3^{\circ}$ Que las ramas se corten como se venía hartamente recalcando en las ordenanzas: «deixant... forca, eo rama, pendó[n], e guia».

50 A.M.O., lib. D-2.216, ff. 7v-8r., año 1548.

51 A.M.O., lib. 152, f. 170v; y lib. 135, f. 123v, años 1681 y 1655, respectivamente.

52 A.M.O., lib. 35, ff. 197r-205r.

53 A.M.O., lib. D-2.216, ff. $7 \mathrm{v}-8 \mathrm{r}$.

54 La participación de Ocaña es evidente: «Nos Philippus... (ordena se respeten los estatutos establecidos por) dilecto nostro Don Ludovico de Ocanya». Biblioteca Pública "Fernando de Loazes", sig. 83-9, año 1625.

55 Para la citas me sirvo de MARTÍNEZ, THOMAS (1703): RECOPILACIÓN/ DE LOS/ ESTATUTOS,/ PRIVILEGIOS, Y OTROS/ REALES ÓRDENES DADOS A LA/ MUY NOBLE, Y MUY LEAL/CIUDAD DE/ ORIHUELA/ PARA SU GOVIERNO./ COMPUESTA.../POR EL DOCTOR ... A.M.O., lib. 2.040, p. 107r-v. 
$4^{\circ}$ Que queda prohibido «tallar de peu — a no ser- pera obrar, ò cubrir alguna casa, palau, ó barraca».

$5^{\circ} \mathrm{Y}$ que para talar cualquier árbol es preciso primero un reconocimiento por parte de los jurados a fin de «senyalar, é senyale la part, y pins que se han de tallar y no se puguen tallar mes».

En la medida que la leña y la madera comenzaron a escasear, el gobierno municipal se hizo más exigente, lo que obligó a los vecinos —en consonancia con estas exigencias - a ser más respetuosos con las ordenanzas municipales que protegían el árbol. Los documentos intensifican el respeto a los Estatutos a lo largo del siglo XVII, ratificando, por un lado, que si mucho es ilegal no es menor lo legal, y, por otro, que el Consell afianza las capacidades decisoria y ejecutiva. Porque si entra dentro de la lógica que lo vecinos, cumpliendo con el Estatuto 40, acudan a solicitar el permiso para hacer carbón, cortar pinos (para obras de casas, barracas, apriscos, etc.), no parece lógico que se acuda a buscar la solicitud para talar un solo árbol, y árbol propio además (Verbigracia: «Joseph Masquefa —que hubo de pedir, y se le concedió, permiso para cortar un pi gran... front la porta de la casa de la sua cañada — que- se á secat ${ }^{56}$ ), a no ser que deba entenderse como ejemplo de reforzamiento del poder municipal. Como lo es también que los señores se vean obligados a cumplir las ordenanzas ${ }^{57}$.

A tenor, pues, de la documentación, los permisos señalan, primero, el potencial del bosque, del árbol más concretamente, y, segundo, las prioridades de los vecinos. Dicho llana y esquemáticamente, los permisos se otorgan por dos motivos: para fabricar carbón vegetal, tan necesario para las cocinas y calefacción, y para extraer madera útil para la construcción. Los testimonios son elocuentes y abundantes, valgan unos casos a modo de ejemplo:

«... pera cubrir una casa que te en la orta partida de Cantallops — se da permiso a Jaume Serra para cortar - trenta pins grosos pera traure sinquanta bigues (...), tallar çent perches y set estants y sinquanta puntals pera adobar dites bar[r]aques (...) A Ginés Aniort se le permitió cortar ramas de pins verts pera alvergue del seu ganado (...) A las monjas de San Sebastián pera cubrir els terrats del monasterio (...) Y a Llorent Miñano — para que — puxa tallar pins verts de peu... fora lo terme de Sent Gines pera fer una barraca en les t[a]h[ull]es que te en lo cami de Almoradí prop la porta de la Corredora.... ${ }^{58}$

\section{¿Reforestación o regeneración?}

Cuando el bosque es capaz de regenerarse por sí mismo, basta con tomar medidas pasivas: prohibir, limitar, vedar. Mas llegado a un cierto punto, a ese límite en que la regeneración natural no puede por sí sola superar la barrera del desastre, es preciso recurrir a la acción: hay que echar una mano a la Naturaleza, hay que reforestar.

Pues bien, si a las fuentes nos atenemos, no se encuentran pruebas de que el Consell, el Gobernador o los vecinos se preocupasen por la reforestación durante los siglos XVI y XVII. Por más que la órdenes reales lo recordasen desde principios del Quinientos, como

56 A.M.O., lib. 158, f. 113r-v., año 1691. Los casos abundan, véanse libros Capitulares y de Clavería de los siglos analizados.

57 El caso citado y, a modo de ejemplo, el de «D[on] Fr[rancisc]o Rois, señor del lloch de Coix —que como todo vecino debe conseguir el permiso para — tallar çent perchas pera cobrir — sus — casas». A.M.O., lib. D-2.273, f. 195v., año1640.

58 A.M.O., lib. D-2.273, f. 195r y 193r, año 1640; lib. 136, f. 4r-v, año 1656, y lib. 147, ff. 101-118, año 1669. A lo largo del estudio se han citado extensamente permisos para carbón. 
la Provisión Real de Carlos I (Zaragoza, 1518). El emperador, preocupado por «la mucha desorden... en el deszepar y talar e cortar de los montes y pinares e otros Árboles», había ordenado a todas las ciudades y villas que averiguasen

«que parte de los términos dehesas de d[ic]has ciudades, villas e lugares se podían poner e plantar algunos montes con el menos daño e perjuyçio que se pudiese... - y- se plantasen montes y pinares, e en los lugares donde no se [h]obiese dispusiçión para ello se plantasen alzes y álamos...» ${ }^{59}$

Las únicas pruebas, los únicos casos documentados sobre reforestación no se refieren nunca al bosque, al árbol silvestre, maderero; sino a plantaciones de moreras, relacionadas con la seda, o a plantaciones ornamentales-recreativas relacionadas con el marco urbano, que se interesan por proporcionar lugares de asueto y paseo para la comunidad ${ }^{60}$. Ni uno ni otro tienen nada que ver con la regeneración del bosque, con la recuperación del árbol maderero. Habrá que esperar al siglo XVIII, ya pasado el primer tercio, para presentar una prueba documental que demuestre el cambio de orientación respecto a la política forestal. El triste panorama en el que se hallaba el bosque al llegar el Siglo de la Ilustración azotó la conciencia vecinal. Tampoco se debe despreciar el cambio de rumbo — de todo signo- que se abrió con las 'luces' de la nueva época, preocupada más que nada por la necesidad de madera para la flota. Quizá la Ilustración alumbró también, si no la visión ecológica, el cuidado por la Naturaleza. Todo, seguramente, coadyuvó para que en 1739 se replantease la urgencia de proceder a la reforestación de la zona más castigada: el realengo ${ }^{61}$. Pero esto ya pertenece a otra época ${ }^{62}$.

\section{Fuentes y bibliografía}

\section{Fuentes}

La documentación original se ha extraído de tres archivos: Archivo Histórico de Orihuela, sección Protocolos; Archivo Municipal de Orihuela, sección Contestador (Actas Capitulares) y Libros de Clavería; y Archivo de la Real Chancillería de Valladolid: Pleitos Civiles (Olvidados), Varela, C. 835-3. En notas a pie de página se precisan los documentos citados.

59 Testimonio recogido del Archivo de la Real Chancillería de Valladolid: Pleitos Civiles (Olvidados), Varela, C. 835-3.

60 Así, entre la abundancia de casos, el de 1660: «que es replanten los dits albers en la dita alameda tots los que seran menester». La orden es de 26 de enero, y el abono de 5 libras y 4 sueldos al plantador del 16 de abril, por haber «plantat çinquanta peus de alams blanchs en la alameda». A.M.O., lib. 141, ff. 17r-v y 59r, respectivamente.

61 En 1739 se intentó una siembra máxima, pero acontecimientos imprevistos lo impidieron: «no haver venido dichos piñones, respectto de que esttos para la expresada siembra se han de sacar de las piñas sin fuego, y no ser tiempo proporcionado para ello — por lo que se- acordó se suspendan las diligencias hastta el año siguientte para que entonces se practique así la siembra de los piñones en los realencos». A.M.O., lib. 193, f. $93 \mathrm{r}$.

62 Al respecto, véase nuestro estudio «Árboles y montes del Vinalopó y l'Alacantí a mediados del siglo XVIII» en Revista del Vinalopó, 10, CEL Petrer, 2007, pp. 187-205. 


\section{Bibliografía}

ALONSO DE HERRERA: Libro de Agricultura, ed. de 1584.

ALONSO MILLÁN, J. (1995): Una tierra abierta. Materiales para una Historia Ecológica de España, Madrid.

BARRIO BARRIO, J. A. (1994): «La ganadería oriolana en el siglo XV: la regulación de los pastos», en Investigaciones Geográficas, núm. 12, Alicante.

BAUER MANDERSCHEID, E. (1980): Los montes de España en la historia. Ministerio de Agricultura. Madrid.

BERNABÉ GIL, D. (1983): «La Vega Baja del Segura en vísperas de la expulsión de los moriscos: estructura de la propiedad de la tierra», en Estructuras y regímenes de tenencia de la tierra en España, Ministerio de Agricultura, Pesca y Alimentación, serie Estudios, pp. 61-74.

- (1989): Hacienda y mercado urbano en la Orihuela foral moderna, Alicante

- (1999-99): «Insalubridad y bonificaciones de almarjales en el Bajo Segura antes de las Pías Fundaciones de Belluga», en Revista de Historia Moderna, n 17, Alicante, pp. 45-72.

CÁNCER, L. A. (1999): La degradación y la protección del paisaje. Madrid.

CAXA DE LERUELA, M.: Restauración de la abundancia de España, ed. de 1631.

COVARRUBIAS, S.: Tesoro de la Lengua Castellana, ed. facsímil. se remata en dos gajos».

GIL OLCINA, A. y CANALES MARTÍNEZ, G. (1988): Residuos de propiedad señorial en España. Perduración y ocaso en el Bajo Segura. Alicante.

GÓMEZ MENDOZA, J.(1967): «La venta de baldíos y comunales en el siglo XVI. Estudio de su proceso en Guadalajara», en Estudios Geográficos, $n^{\circ} 109$, pp. 499-559.

MARTÍNEZ, THOMAS (1703): Recopilación/ de los/Estatutos,/ Privilegios, y otros/Reales Órdenes dados a la/ muy noble, y muy leal/ ciudad del Orihuela/ para su govierno./ Compuesta.../ por el doctor... Orihuela.

MARTÍNEZ PATERNA, F. (1632): Historia/ de la/ Ciudad de Orihuela/ y de sus pueblos oritanos; tratase del su obispado, gobernación y/ baylía general; de los montes, de los ríos y/ fuentes e islas, de los promontorios, senos y puertos/ que tiene esta provincia, Orihuela.

MATEO RIPIO, V. (1994): Oligarquía y poder en el siglo XVIII. Alicante.

NIETO FERNÁNDEZ, A.(1988): Orihuela en sus documentos, II. Economía y sociedad, siglo XIVXIX. Agricultura, Ganadería, Industria y Comercio, Murcia.

OJEDA NIETO, J. (1989): Alaejos, un pueblo de Castilla la Vieja en la España del siglo XVI, Valladolid.

- (1997): Comendadores y vasallos (La Orden de San Juan y el Partido de Valdeguareña), Zamora.

- (2007): «Árboles y montes del Vinalopó y l'Alacantí a mediados del siglo XVIII», en Revista del Vinalopó, 10, CEL, Petrer, pp. 187-205.

VILAR, J. B. (1981): Orihuela, una ciudad valenciana en la España Moderna. Historia de la ciudad y obispado de Orihuela, IV, vol. III. 